\title{
Concepções sobre a Relação Ensino-Pesquisa no/do Currículo da Licenciatura em História da UFPE em Contexto de Reforma Curricular
}

\author{
CAMELO, Danielle \\ BATISTA NETO, José2
}

\section{RESUMO}

O presente artigo tem como objetivo analisar concepções construídas por docentes e funcionário do corpo técnico-administrativo do curso de licenciatura em História da Universidade Federal de Pernambuco sobre a relação ensinopesquisa proposta pelo curso a partir de sua reforma curricular, implantada em 2012.2. Para construímos a pesquisa, utilizamos a entrevista semiestruturada como instrumento metodológico. Foram entrevistados/as docentes do curso e funcionário do corpo técnico administrativo. A análise dos dados foi realizada a partir da produção teórica de Soares e Cunha (2017); Cunha (2011); Monteiro e Penna (2011); Tardif (2002); Freire (1997), e categorizada a partir da técnica da Análise de Conteúdo de Bardin. As entrevistas mostraram divergências entre as concepções dos sujeitos sobre o currículo do curso, o processo de reforma e, dentro disto, acerca da concepção teoria-prática, concebida como indissociável por um grupo de sujeitos e como dicotômica por outro grupo.

Ensino-Pesquisa. Formação de Professores/as. Licenciatura.

\section{Conceptions about the Teaching-Research Relationship in/on the Undergraduate Curriculum in the History of the UFPE in the Context of Curricular Reform}

\begin{abstract}
The objective of this article is to analyze conceptions built by professors and employees of the technical-administrative staff of the degree course in History of the Federal University of Pernambuco about the teaching-research relationship proposed by the course from its curricular reform, implemented in 2012.2 To build the research, we use the semi-structured interview as a methodological tool. The course teachers and administrative staff were interviewed. The data analysis was
\end{abstract}

\footnotetext{
${ }^{1}$ Doutora em Educação pela UFPE. Mestra em Educação pela UFPE. Licenciada em História pela UFPE. Email: profdaniellecamelo@gmail.com. Lattes:

http://lattes.cnpq.br/2271572660654188. Orcid: https://orcid.org/0000-0002-3484-4987.

${ }^{2}$ Doutor em Ciências da Educação e Professor Titular do Departamento de Métodos e

Técnicas de Ensino, do Programa de Pós-graduação em Educação da Universidade Federal de Pernambuco. Email: netojose31@gmail.com. Lattes: http://lattes.cnpq.br/4598908452423232.
} 
performed from the theoretical production of Soares e Cunha (2017); Cunha (2011); Monteiro and Penna (2011); Tardif (2002); Freire (1997), and categorized from the technique of Content Analysis of Bardin. The interviews showed divergences between the subjects' conceptions about the course curriculum, the reform process and, within this, about the theory-practical conception, conceived as inseparable by one group of subjects and as dichotomous by another group.

Teaching-Research. Teacher Training. Bachelor's Degree.

\section{Concepciones sobre la Relación de Enseñanza-Investigación en/del Currículo de Licenciatura en Historia de la UFPE en el Contexto de la Reforma Curricular}

\section{RESUMEN}

El propósito de este artículo es analizar las concepciones construidas por profesores y funcionarios del personal técnico-administrativo del curso de Historia en la Universidad Federal de Pernambuco sobre la relación de enseñanza-investigación propuesta por el curso a partir de su reforma curricular, implementada en 2012.2. Para construir la investigación, utilizamos la entrevista semiestructurada como herramienta metodológica. Los profesores y el personal técnico administrativo fueron entrevistados. El análisis de datos se realizó con base en la producción teórica de Soares y Cunha (2017); Cunha (2011); Monteiro y Penna (2011); Tardif (2002); Freire (1997), y categorizado según la técnica de análisis de contenido de Bardin. Las entrevistas mostraron divergencias entre las concepciones de los sujetos sobre el currículo del curso, el proceso de reforma y, dentro de esto, sobre el concepto de teoría-práctica, concebido como inseparable por un grupo de sujetos y como dicotómico por otro grupo.

Enseñanza-Investigación. Formación del profesorado. Licenciatura.

\section{Concezioni sulla relazione insegnamento-ricerca in / dal corso di laurea in Storia dell'UFPE Curriculum in Curriculum Reform Context}

\section{RIASSUNTO}

Questo articolo ha lo scopo di analizzare le concezioni costruite da professori e dipendenti del personale tecnico-amministrativo del corso di Storia dell'Università Federale del Pernambuco sul rapporto insegnamento-ricerca proposto dal corso dalla sua riforma curriculare, attuato nel 2012.2. Per costruire la ricerca, abbiamo usato l'intervista semi-strutturata come strumento metodologico. Sono stati intervistati insegnanti e personale amministrativo del corso. L'analisi dei dati è stata eseguita sulla base della produzione teorica di Soares e Cunha (2017); Cunha (2011); Monteiro e Penna (2011); Tardif (2002); Freire (1997), e classificato usando la tecnica di Content Analysis di Bardin. Le interviste hanno

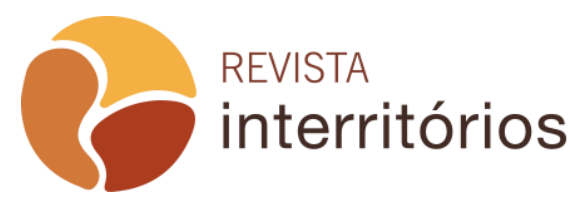

Interritórios | Revista de educação Universidade Federal de Pernambuco, Caruaru, BRASIL | V. 6 n. 11 [2020] 
mostrato divergenze tra le concezioni dei soggetti sul curriculum del corso, il processo di riforma e, all'interno di questo, sulla concezione teoria-pratica, concepita come inseparabile da un gruppo di soggetti e come dicotomica da un altro gruppo.

Insegnamento-Ricerca. Formazione degli insegnanti. La laurea.

\section{INTRODUÇÃO}

A relação ensino-pesquisa na formação docente vem ganhando, cada vez mais, espaço nos debates do campo educacional, sobretudo a partir dos anos 2000 , quando vivenciamos a implementação de novas diretrizes nacionais ${ }^{3}$ para cursos de licenciatura, cuja redação aponta indissociabilidade da relação ensinopesquisa como fundamental para o processo formativo. Tal relação é tema central deste artigo que tem como objetivo apresentar uma análise de concepções construídas por docentes e funcionário do corpo técnicoadministrativo do curso de licenciatura em História da Universidade Federal de Pernambuco (UFPE) sobre a relação ensino-pesquisa proposta pelo curso a partir de sua reforma curricular, implantada em 2012.2.

O interesse por pesquisar a formação de professores/as do curso de licenciatura em História da UFPE decorre das nossas experiências no processo da formação inicial, da formação continuada e da prática docente. Enquanto estudante de Licenciatura em História pela Universidade Federal de Pernambuco tivemos a formação inicial ${ }^{4}$ baseada na estrutura curricular comumente dominada pelo "modelo 3+1". Tal denominação é justificada por um currículo que direciona os três primeiros anos do curso exclusivamente aos componentes curriculares referentes ao campo da História, ou seja, os estudantes do bacharelado e da licenciatura compartilhavam os mesmos componentes curriculares sem sequer haver algum contato - teórico ou prático - com conteúdos da área de Educação. Somente no último ano, cursávamos as disciplinas voltadas à Educação e nos aproximávamos da escola e da educação básica a partir dos estágios que se desdobravam em dois semestres: Prática de Ensino de História I e Prática de Ensino de História II.

\footnotetext{
${ }^{3}$ Resolução CNE/CP n¹/2002, Resolução CNE/CP n²/2002 e Resolução CNE/CO n¹/2015.

${ }^{4}$ Compreendemos que a formação docente é permanente e acontece em diversos espaços além das instituições formativas, porém corroboramos com a concepção de que as instituições são espaços privilegiados de formação e ofertam uma formação própria ao docente. Chamamos de formação inicial a primeira etapa da formação institucional dos/as futuros/as docentes e que confere licença pelo Estado para o exercício profissional.
} 
O curso de História da UFPE permitia ao/a estudante ingressante obter duas habilitações em um mesmo curso de graduação. O/a discente poderia formar-se bacharel e/ou licenciado/a. Atualmente, a universidade oferta dois cursos que apresentam organização curricular específica, cada um, porém, no período ao qual nos referimos (2001-2005), a formação só se diferenciava a partir do quarto ano quando o/a estudante interessado no bacharelado cursava disciplinas distintas daqueles que decidia caminhar para uma formação de licenciado/a. O currículo da licenciatura, portanto, estava contaminado por conteúdos que a ele emprestava um perfil bacharelizante, considerado como a base da formação. Este cenário supunha uma compreensão segundo a qual a formação de professor reduzia-se ao momento de aplicação de toda teoria aprendida ao longo dos anos no campo de exercício pré-profissional, a escola.

Os aspectos apresentados acima nos aproximaram do debate teórico acerca da formação de professores/as, em especial, a formação de professores/as de História. Passamos a nos inquietar com a hierarquização de saberes vigente na cultura institucional que passava a cristalizar o papel de coadjuvante dos estudos relativos à Educação. A noção de papel secundário, ou até mesmo descartável, defendida por inúmeros estudantes e professores do próprio curso, a que se atribui à formação pedagógica, causava-nos incômodo.

Nesse contexto, enquanto estudante do curso de licenciatura em História, identificamos dois aspectos decisivos para a construção da ideia de desvalorização do saberes pedagógicos: a) a organização curricular do curso de História; b) a compreensão da fragilidade da relação teoria-prática e da relação ensino-pesquisa, por parte dos/as estudantes e de certos docentes, especialmente da área de História.

No segundo semestre de 2012, o curso de licenciatura em História da UFPE implementou uma reforma curricular que atribuía perfil curricular próprio ao curso de licenciatura. A reforma baseava-se, dentre outras legislações, no que determinava a Resolução CNE/CP n¹/2002. O documento instituiu novas Diretrizes Curriculares Nacionais da Formação de Professores para o Magistério na Educação Básica, em nível superior, curso de licenciatura, de graduação plena. A partir de tais diretrizes, os cursos de licenciatura, dentre eles o de História, precisavam passar por uma reforma curricular. A reforma tocava principalmente 0 âmbito da formação pedagógica, pois instituía a obrigatoriedade de um currículo específico para as licenciaturas, que se configuraria em um projeto pedagógico próprio. Instituía a prática como componente curricular a ser cumprida desde o período inicial do curso, ampliava a carga horária de estágio, determinava seu início a partir da segunda metade do curso e recomendava a inserção de componentes curriculares referentes ao campo da educação desde o início do curso. 
Diante deste cenário, passamos a construir uma pesquisa - que resultou em nossa tese de doutorado - cujo objetivo geral consistia em compreender concepções de formação pedagógica ${ }^{5}$ do/no curso de licenciatura em História da Universidade Federal de Pernambuco a partir da sua reforma curricular de 2012.2. A pesquisa contou com a análise de documentos - incluindo resoluções e pareceres em nível nacional e institucional, bem como projetos pedagógicos do curso de licenciatura em História e matriz curricular do curso - e entrevista semiestruturada com docentes, funcionário do corpo técnico administrativo, estudantes de períodos finais e egressos. As categorias de análise foram organizadas a partir dos dados coletados diante dos procedimentos e instrumentos metodológicos, e dos sujeitos participantes da pesquisa. $\mathrm{O}$ artigo, ora apresentado, trata, especificamente, da categoria denominada "relação ensino-pesquisa", construída a partir das entrevistas realizadas com docentes do curso e funcionário técnico administrativo. A seção seguinte debruçar-se-á sobre as questões metodológicas da pesquisa que resultou na produção deste texto.

\section{Os caminhos da pesquisa}

Ao lançarmos os olhares para os encaminhamentos metodológicos desta investigação, percebemos que foram construídos num constante movimento de leituras, ressignificações e restruturações a partir da relação entre o objeto, os objetivos, o aporte teórico e as possibilidades de percurso para coleta e análise dos dados. Compreendemos que um percurso metodológico tem início não só no momento em que nos deparamos com as fontes a serem analisadas, mas que principia desde o instante em que as inquietações deram origem à construção do objeto de pesquisa. Corroboramos com a ideia de Minayo (2006) de que "nada pode ser intelectualmente um problema, se não tiver sido, em primeiro lugar, um problema da vida prática”. (MINAYO, 2006, p.17).

Como dito na seção introdutória, o trato com a relação ensino-pesquisa é o recorte de uma pesquisa mais ampla que buscou analisar a formação pedagógica do/no curso de licenciatura em História da UFPE. Um dos objetivos específicos da investigação consistia em analisar o que pensam sujeitos participantes da reforma (dentre eles/as, conceptores/as do Projeto Pedagógico do Curso) e docentes que vivenciam o currículo reformulado, do curso de Licenciatura em História da UFPE, sobre o contexto da reforma e o perfil (11131) que dela resultou. Para alcançar estes objetivos, recorremos à entrevista

\footnotetext{
${ }^{5}$ Denominamos de formação pedagógica o processo formativo institucional no qual os docentes em formação constroem os saberes referentes ao campo da educação, ou seja, o processo de construção de seus saberes pedagógicos.
}

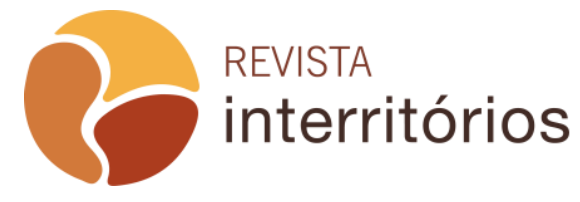

Interritórios | Revista de educação Universidade Federal de Pernambuco, Caruaru, BRASIL | V. 6 n. 11 [2020] 
semiestruturada enquanto instrumento metodológico. A partir do referido objetivo e do referido instrumento, construímos a categoria da relação ensino-pesquisa na formação de professores/as.

Os critérios de escolha dos sujeitos para responderem às entrevistas foram construídas ao longo da pesquisa de campo, em decorrência das nuances e realidades não previstas durante a coleta de dados. De modo geral, os/as docentes escolhidos/as foram aqueles/as que participaram do processo da reforma curricular do curso e que vivenciam o currículo reformulado, tendo em vista que ainda ocupam o cargo docente e/ou de gestão.

Foram entrevistados/as 4 (quatro) professores/as do Departamento de História (D.H), do Centro de Filosofia e Ciências Humanas (CFCH) e 2 (duas) do Departamento de Métodos e Técnicas de Ensino (DMTE) - vinculado ao Centro de Educação. Dentre as duas professoras do DMTE, uma delas compõe o corpo docente do curso de licenciatura em História e a outra, atuante no curso de licenciatura em Letras, teve participação fundamental nos Fóruns de Licenciatura da UFPE que discutiam as reformas curriculares desses cursos, tendo ocupado a função de Coordenadora das Licenciaturas Diversas.

Além de professores/as também entrevistamos um funcionário da secretaria do Departamento de História. A escolha de um membro do quadro Técnico Administrativo deu-se pelas particularidades do curso de História. $O$ técnico, formado em Licenciatura Plena em História pela UFPE, trabalha junto à Coordenação desse curso há mais de duas décadas. Pelo tempo de serviço, possui conhecimentos minuciosos sobre reformas curriculares, legislações e processos administrativos da Universidade, bem como sobre o cotidiano do curso, o que o terna, sem dúvida, um informante chave para a pesquisa. Ademais, vale salientar, que o mesmo participou, como representante do departamento, de inúmeras reuniões dos Fóruns de Licenciatura. Nesse sentido, o T.A mostrou-se como um sujeito importante para conhecermos os processos de tensões e conflitos em torno da reforma curricular.

Tivemos, portanto, um total de 7 (sete) docentes entrevistados e um funcionário técnico administrativo. $O$ quadro abaixo faz o mapeamento do perfil destes sujeitos e busca esclarecer a identificação utilizada para nos referirmos a eles/as no decorrer da pesquisa; o cargo que ocupa na Universidade; o Departamento ao/à qual estão vinculados/as; o tempo de atividade na UFPE; se possuem experiência como professor/a na Educação Básica e/ou outros órgãos de gestão, bem como se ocupam ou já ocuparam cargos de gestão na Universidade e suas respectivas titulações.

Quadro 01: Perfil dos docentes e funcionário técnico-administrativo participantes da pesquisa 


\begin{tabular}{|c|c|c|c|c|c|c|}
\hline IDENTIFICAÇÃO & CARGO & DEPARTAMENTO & $\begin{array}{c}\text { TEMPO DE } \\
\text { ATIVIDADE NA UFPE } \\
\end{array}$ & $\begin{array}{c}\text { EXPERIÊNCIA } \\
\text { EDUCAÇÃO BÁSICA } \\
\end{array}$ & $\begin{array}{c}\text { CARGO DE } \\
\text { GESTÃO NA UFPE }\end{array}$ & TITULAÇÃO \\
\hline P.HIST.1 & DOCENTE & HISTÓRIA & 21 anos & Sim & $\begin{array}{l}\text { Coordenador de } \\
\text { Curso de Graduação }\end{array}$ & $\begin{array}{l}\text { Doutorado em } \\
\text { História Social }\end{array}$ \\
\hline P.HIST.2 & DOCENTE & HISTÓRIA & 15 anos & Não & $\begin{array}{l}\text { Coordenadora do } \\
\text { Curso de Bacharelado }\end{array}$ & $\begin{array}{l}\text { Doutorado em } \\
\text { História Social }\end{array}$ \\
\hline P.HIST.3 & DOCENTE & HISTÓRIA & 23 anos & Sim & $\begin{array}{l}\text { Coordenadora do Curso } \\
\text { e Chef do Departamento }\end{array}$ & $\begin{array}{l}\text { Doutorado em } \\
\text { História Social }\end{array}$ \\
\hline P.HIST.4 & DOCENTE & HISTÓRIA & 27 anos & $\begin{array}{c}\text { Sim } \\
\text { (docente,ocupou cargo de } \\
\text { gestão na Secretaria de } \\
\text { Educação-PE) }\end{array}$ & $\begin{array}{l}\text { Coordenador de } \\
\text { Curso de Graduaçãa }\end{array}$ & $\begin{array}{l}\text { Pós-Doutorado } \\
\text { em História }\end{array}$ \\
\hline P.CE 1 & DOCENTE & DMTE & 10 anos & Sim & $\begin{array}{c}\text {-Membro permanente da } \\
\text { Comissão do Pibic; } \\
\text {-Coordenadora das } \\
\text { Licenciaturas; } \\
\text { - Membrodo Comitê de } \\
\text { Ética da UFPE }\end{array}$ & $\begin{array}{l}\text { Doutorado } \\
\text { em História }\end{array}$ \\
\hline P.CE 2 & DOCENTE & DMTE & 21 anos & $\operatorname{sim}$ & $\begin{array}{l}\text { Coordenadora das } \\
\text { Licenciaturas }\end{array}$ & $\begin{array}{l}\text { Doutora } \\
\text { em Linguistica }\end{array}$ \\
\hline TEC. 1 & TÉCNICO & HISTÓRIA & Superior a 20 anos & Não & Não & $\begin{array}{l}\text { Graduação } \\
\text { em História }\end{array}$ \\
\hline
\end{tabular}

Fonte: Produção de autoria da pesquisadora a partir de dados cedidos pelos sujeitos da pesquisa.

Com base no perfil dos sujeitos, identificamos que temos um grupo de professores/as e funcionário veteranos/as nos cursos a que estavam vinculados. O tempo de atividade pode ser um dado explicativo para os conhecimentos que possuem acerca do curso de História. No caso da docente do curso de licenciatura em Letras, tem envolvimento com os debates sobre cursos de licenciatura e a vivência como coordenadora desses cursos na UFPE. Outro dado relevante é que somente uma docente não apresenta experiência na Educação Básica. No capítulo referente à análise das entrevistas, veremos em que medida tais experiências podem ou não influenciar as compreensões sobre a formação de professores/as.

A análise dos dados coletados a partir da entrevista semiestruturada foi baseada na Análise de Conteúdo na perspectiva de Bardin (1977). Segundo a autora, a Análise de Conteúdo oferece-nos suportes para compreendermos diversos tipos de comunicação.

A análise de conteúdo é um conjunto de técnicas de análise de comunicações.

Não se trata de um instrumento, mas um leque de apetrechos; ou, com maior rigor, será um único instrumento, mas marcado por uma grande disparidade de formas e adaptável a um campo de aplicação muito vasto: as comunicações (BARDIN, 1997, p. 31).

As comunicações, de acordo com Bardin, podem circular por meio de diversos veículos e materializar-se em diversos suportes. De acordo com Minayo (2006), "a análise de conteúdo diz respeito a técnicas de pesquisa que permitem 
tornar replicáveis e válidas inferências sobre dados de um determinado contexto, por meio de procedimentos especializados e científicos" (MINAYO, 2006, p.303).

A relação ensino-pesquisa apareceu com destaque nas concepções trazidas pelos/as docentes e funcionário técnico-administrativo quando questionados/as sobre a reforma curricular do curso de licenciatura em História e, a partir dela, a criação de um curso com autonomia e identidade própria em relação ao bacharelado. Partindo disto, analisamos, neste texto, a categoria referente à relação ensino-pesquisa a partir de duas subcategorias norteadoras: a relação entre o curso de licenciatura e do bacharelado, e a relação entre os saberes disciplinares e os saberes pedagógicos na formação docente.

\section{Relação ensino-pesquisa na formação de professores/as: um debate teórico}

Tratar a relação ensino-pesquisa em cursos de licenciatura requer um debate acerca do papel das Universidades e das escolas enquanto espaços formativos. Autores como Soares e Cunha (2017) reafirmam a importância e urgência de refletimos sobre a qualidade das universidades e suas finalidades. Tardif (2002) também trata dos espaços acadêmicos, especificamente de formação de professores/as, e sua relação com o ambiente escolar. Em ambos os trabalhos, os/as pesquisadores/as afirmam a responsabilidade da universidade no que se refere à relação ensino-pesquisa.

No Brasil, a história da formação de professores/as, mostra que durante muito tempo as universidades foram compreendidas como lócus de produção de conhecimento, enquanto as escolas eram concebidas como lugares de reprodução e aplicação das teorias. Diante desta perspectiva, os cursos de formação de professores/as distanciavam-se da proposta formativa que concebia o/a professor/a da educação básica também como pesquisador/a. $\mathrm{Na}$ mesma medida, não compreendia que o/a docente/a do ensino superior teria também finalidades pedagógicas em suas práticas.

Soares e Cunha (2017) afirmam que a relação ensino-pesquisa nas universidades é capaz de promover aprendizagens significativas por parte dos sujeitos em formação. A prática pedagógica institucional baseada nesta relação indissociável promoveria, para os/as autores/as, a qualidade dos cursos de graduação. Os estudos seriam permeados por vivências fundamentais à construção de conhecimentos: 
a observação, busca de informação, realização de pesquisa que permita sintetizar, identificar, derivar, retrabalhar conteúdos conceituais, procedimentais e atitudinais adquiridos pelo estudante. A dúvida e a crítica são assumidas como elementos fundantes do processo ensino-aprendizagem. (SOARES; CUNHA, 2017, p. 323).

Ao direcionarmos as proposições dos/as autores/as para a formação inicial de professores/as, visualizamos um projeto de formação cuja relação ensino-pesquisa permeia todo o processo formativo corroborando, assim, com a concepção de que docentes da educação básica também são professores/aspesquisadores/as.

O ensino com pesquisa é a forma mais avançada e inovadora de relação entre teoria e prática, concorrendo, portanto, para a qualidade concebida como transformação. Baseia-se na problematização, questionamento e criatividade suscitando um engajamento ativo dos estudantes em atividades de investigação e, portanto, contribuindo para processo de aprender a aprender, aprender a compreender e intervir na realidade. (SOARES; CUNHA, 2017, p. 323).

Nessa mesma direção, Freire (1997) reforça a importância do estudo na prática de ensino. Quando se refere ao ato de estudar, o autor está fazendo referência à atividade investigativa e aos investimentos teóricos que fundamentam a prática dos/as professores/as da educação básica. No processo formativo, o estudo corresponde ao conhecimento que é socializado e produzido nas instituições formadoras.

Partamos da experiência de aprender, de conhecer, por parte de quem se prepara para a tarefa docente, que envolve necessariamente estudar. Obviamente, minha intenção não é escrever prescrições que devam ser rigorosamente seguidas, o que significaria uma chocante contradição com tudo o de que falei até agora. Pelo contrário, o que me interessa aqui, de acordo com o espírito mesmo deste livro, é desafiar seus leitores e leitoras em torno de certos pontos ou aspectos, insistindo em que há sempre algo diferente a fazer na nossa cotidianidade educativa, quer dela participemos como aprendizes, e portanto ensinantes, ou como ensinantes e, por isso, aprendizes também. (FREIRE, 1997, p. 19).

Para promover a compreensão acerca da importância do estudo, da prática investigativa na atividade docente, os cursos de licenciatura precisam ser forjadores de práticas pedagógicas curriculares cuja relação ensino-pesquisa permeia prática docente e discente. O/a professor/a formador/a é pesquisador/a

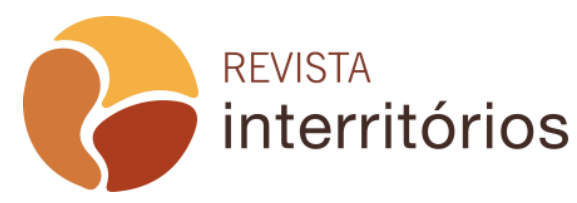

Interritórios | Revista de educação Universidade Federal de Pernambuco, Caruaru, BRASIL | V. 6 n. 11 [2020] 
porque uma das principais finalidades da universidade é a pesquisa. O/a professor/a em formação também é pesquisador/a, pois sua prática necessita de reflexividade.

No contexto das práticas pedagógicas os desafios têm sido intensos. Entre eles, um dos mais exigentes está o de pensar a dimensão superior que caracteriza os estudos do terceiro grau e a condição universitária desses estudos. Para alguns estudiosos essa condição se estabelece pela relação ensino e pesquisa que caracteriza esse nível de educação. Para outros, a denominação de superior significa uma condição de elitização, explicitando que 0 acesso a esse grau de ensino deve pautar-se pela meritocracia e seletividade. Há, ainda, os que creem que o adjetivo superior está ligado ao mundo das profissões e que algumas delas exigem uma preparação mais intensa na sua base teórica. (CUNHA, 2011, p. 444).

Os desafios em construir práticas pedagógicas baseadas na indissociabilidade ensino-pesquisa, em curso de formação de professores/as, são intensificados na medida em que a escola e a prática pedagógica não são vistas como espaços e situações de produção de conhecimento. Tardif (2002) afirma que a prática pedagógica é fonte de construção de teorias que alimentarão novas práticas. Este movimento é denominado pelo autor como "epistemologia da prática profissional". Os saberes mobilizados e utilizados pelos/as professores/as no exercício de sua profissão não só fundamentam a prática pedagógica como promove a produção de novos saberes.

\begin{abstract}
A finalidade de uma epistemologia da prática profissional é revelar esses saberes, compreender como são integrados concretamente nas tarefas dos profissionais e como estes o incorporam, produzem, utilizam, aplicam e transformam em função dos limites e dos recursos inerentes às suas atividades de trabalho. Ela também visa compreender a natureza desses saberes, assim como o papel que desempenham tanto no processo de trabalho docente quanto em relação à identidade profissional dos professores. (TARDIF, 2002, p. 256).
\end{abstract}

Ao direcionarmos o debate acerca da relação ensino-pesquisa na formação e na prática de professores/as de História, é importante ter clareza que o principal campo de pesquisa destes/as docentes é o ensino da história escolar. Partimos do pressuposto de Monteiro e Penna (2011) de que o ensino de história não se configura apenas como objeto de pesquisa, mas sim como campo. Esta concepção se justifica pelo fato das pesquisas acerca do ensino de História versarem não só sobre as metodologias de ensino, mas também sobre recursos didáticos, planejamento, avaliação das

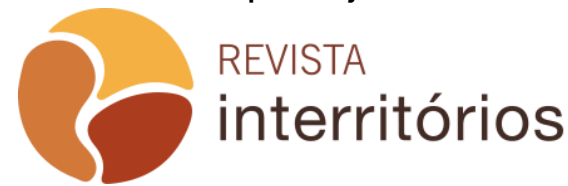

Interritórios | Revista de educação Universidade Federal de Pernambuco, Caruaru, BRASIL | V. 6 n. 11 [2020] 
aprendizagens, políticas educacionais, políticas curriculares, diretrizes curriculares, relações de gênero, relações étnico-raciais, dentre outras.

O vasto campo de pesquisa permite-nos reforçar a importância do diálogo entre os saberes disciplinares e pedagógicos. Monteiro e Penna (2011) desenvolveram uma pesquisa cujo objetivo consistia em analisar em que medida alguns/mas docentes de História construíam suas práticas de ensino a partir do diálogo entre o conteúdo histórico e as questões pedagógicas. Os/as autores/as buscaram observar aulas da disciplina de História em escolas do estado do Rio de Janeiro. Trouxeram como exemplo explicativo a narrativa de um docente acerca da Primeira República, em especial sobre a "política do café com leite"6.

Segundo os/as autores/as, o docente apresenta em seu discurso uma visão revisionista da História do Brasil, pois desconstrói conceitos culturalmente consolidados acerca da "política do café com leite". Além dos investimentos de pesquisa no campo historiográfico, o docente apresentou estratégias que facilitassem a compreensão de seu conteúdo por parte dos estudantes.

Esse trecho expressa uma construção do saber escolar, explicação que busca tornar compreensível para os alunos o significado de café com leite na caracterização da política desenvolvida na Primeira República brasileira. Tema abordado a partir de exigências do currículo escolar é explicado pelo professor com base em referências provavelmente já conhecidas por eles a partir de estudos anteriores. A metonímia configurada na expressão café com leite é, ao mesmo tempo, explicada e desconstruída, pois o professor afirma, com base em prova hoje em dia, que a questão não era o leite pensado a partir da produção de gado, e sim o fato de que Minas era, também, importante produtora de café. Identificamos, aqui, a ação do professor que age como narrador ao articular sujeitos históricos - os fazendeiros - em um determinado tempo - a primeira República - em uma intriga que ele começa a desvendar - as alianças e interesses desses grupos para a manutenção do poder. Ele busca estabelecer um fio de sentido que organiza as informações apresentadas e, neste processo de mobilização de saberes, ele explica ao mesmo tempo em que narra, sem fazer menções explícitas a autores e suas pesquisas (não é um texto científico). O recurso à prova é utilizado, uma vez que permite

\footnotetext{
${ }^{6} \mathrm{O}$ conteúdo compõe o currículo do nono ano do ensino fundamental e do terceiro ano do Ensino Médio. A Primeira República corresponde ao período da História do Brasil onde foi instaurado o regime republicano. Tem início em 1889, com a chegada do Marechal Deodoro da Fonseca à presidência, e finda em 1930 com ascenção de Getúlio Vargas ao poder. A "política do café com leite" diz respeito a uma prática política, característica deste período, cujo objetivo era manter a hegemonia do poder político nas mãos das oligarquias cafeeiras, especialmente da região de São Paulo e das Minas Gerais.
}

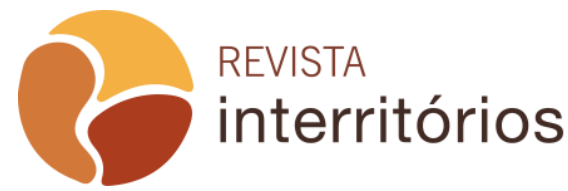

Interritórios | Revista de educação Universidade Federal de Pernambuco, Caruaru, BRASIL | V. 6 n. 11 [2020] 
passar a imagem de um professor atualizado com a produção historiográfica recente. (MONTEIRO; PENNA, 2011, p. 201).

O estudo socializado pelos/as referidos/as autores/as nos serve de exemplo para que possamos esclarecer e reforçar a importância da relação ensino-pesquisa na formação docente na qual o maior desafio consiste em construir dialogicidades entre o saber disciplinar e o saber pedagógico. Se assim não o for, corre-se o risco de formar professores/as de História com base num perfil bacharelizante cuja compreensão de pesquisa destina-se apenas ao campo historiográfico.

\section{Relação ensino-pesquisa na formação de professores/as de história da UFPE}

Historicamente, o curso de licenciatura em História esteve atrelado ao bacharelado. No caso da UFPE, vimos que, pela primeira vez, com a reforma curricular de 2012.2, o curso de licenciatura conquistou sua autonomia pautada na concepção de que a formação docente é um processo distinto tendo a formação pedagógica, um papel fundamental neste processo.

Segundo as concepções de docentes e funcionário T.A, percebemos que havia concepções diferentes acerca do lugar da licenciatura em relação ao bacharelado se compararmos os depoimentos dos/as docentes do Departamento de História e do Centro de Educação. Para os membros do D.H, a licenciatura deveria estar ligada ao bacharelado, pois, dessa forma, garantirse-ia qualidade na formação. Por outro lado, as docentes entrevistadas do C.E advogaram pela autonomia do curso de licenciatura por compreenderem as especificidades e complexidades da formação de professores/as.

A ideia da formação em licenciatura como complementar ao bacharelado apareceu na análise do professor P.Hist.1 que tomou como referência o perfil curricular da USP onde a formação de bacharel é obrigatória e precede ao ingresso na licenciatura: "Então, o curso de História é esse aqui! A licenciatura se agrega a isso aqui, né? Com uma certa... com um certo conjunto de disciplina, carga horária, etc". (P.HIST1) (grifos nossos).

De acordo com P.Hist1, a formação em bacharelado deveria ter a primazia. A licenciatura não fora compreendida como curso autônomo, mas sim como complementar, como algo que "se agrega" ao bacharelado. $O$ depoimento trouxe uma concepção acerca da formação de professores/as cujo foco deveria ser a construção de saberes disciplinares e da prática investigativa no campo historiográfico. Nessa mesma perspectiva, P.Hist3 afirmou que, para 0 Departamento de História, o interesse circulava - e ainda circula - em torno do

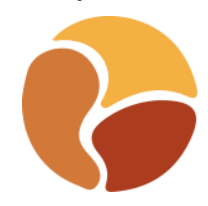


objetivo de formar "professores/as historiadores/as", ou seja, aqueles que privilegiassem a pesquisa histórica em sua formação, mas que também tivessem a habilitação - advinda da formação complementar - para atuar na educação básica.

Quando questionada sobre as discussões que permearam o contexto da reforma curricular do curso, a docente afirmou e quis fazer crer, que mesmo antes da Resolução CNE/CP n 1/2002, o Departamento de História já pensava em mudanças no currículo do curso, porém não se cogitava a autonomia da licenciatura em relação ao bacharelado. Segundo P.Hist3, "pensou-se em manter as duas formações dentro de uma perspectiva que a gente achava que a possibilidade de formar também um professor que fosse historiador. Era essa a ideia da gente. Foi nesse sentido que a gente pensou a reforma." (P.HIST3).

Em um momento da sua entrevista, o funcionário do Departamento de História, Tec1, afirmou que a ideia de formar, prioritariamente, o/a historiador/a era hegemônica no Departamento. "Há uma concepção no Departamento de História de que nós não formamos somente professores de História, mas historiadores. Historiadores habilitados a serem professores e professores habilitados a serem historiadores." (TEC1).

Ambos os trechos dos testemunhos mostraram que a concepção de pesquisa na formação de professores/as é sinônimo de pesquisa no campo historiográfico. De acordo com os depoimentos, seria somente na relação com o bacharelado que o curso de licenciatura garantiria a prática da pesquisa. Não houve evidência de que se cogitaria a ideia de que o campo da Educação poderia configurar-se como campo de pesquisa, tampouco a formação pedagógica poderia promover prática de pesquisa a partir da indissociabilidade na relação ensino-pesquisa.

A primazia do bacharelado, aos olhos do Departamento de História, foi explicitado pela professora $\mathrm{P}$. Hist4 quando questionada sobre 0 "desmembramento" da licenciatura e, consequentemente, sua autonomia. Em decorrência de suas experiências na Secretaria de Educação de Pernambuco como professora, gestora e formadora, a docente apresentou uma concepção um pouco diferente daquelas apresentadas pelos seus/suas colegas entrevistados/as. Ela demonstrou maior compreensão acerca da importância da formação pedagógica, mas, ainda assim, revela a preferência pela formação que coloca o bacharelado como condição para a formação do/a licenciando/a.

Olhe... há uma questão muito séria, desde o início, é... eu não diria que atormenta, mas que está por trás das questões do curso de História: é essa questão do bacharelado. 
O bacharelado é muito importante para o curso de História porque foi a vida toda uma espécie de menina dos olhos do curso de História que era o bacharelado. Que era através do bacharelado que o aluno entraria na pesquisa, e eu repito mais uma vez: não é essa a minha percepção.

Eu acho que o bacharel e o licenciado tem que ter a mesma formação em termo de conteúdos específicos, mas a gente sempre teve um olhar carinhoso em relação ao bacharelado porque o curso de História da Federal, me parece, que era o único do estado que oferecia as duas habilitações: bacharelado e licenciatura. (P.HIST4) (grifos nossos).

O trecho permite-nos identificar a concepção de que há uma prioridade em relação à formação para a pesquisa no campo historiográfico do que qualquer outro tipo de formação. No caso da licenciatura, as especificidades da formação pedagógica foram tratadas como secundárias se compararmos ao valor atribuído aos saberes disciplinares. Este aspecto pode estar relacionado à desvalorização porque passa a atividade docente em nosso país. O status social do/a pesquisador/a em detrimento do status do/a professor/a também leva o Departamento a reforçar a preferência pela formação por meio do bacharelado ao invés de formar docentes.

Neste mesmo caminho, a professora P.Hist2, afirmou: "o Departamento de História é muito envolvido com a graduação. Eles têm uma... São muito sérios com a graduação e quando tá todo mundo contra o bacharelado, 0 Departamento aqui tá sempre querendo preservar, sabe?" (grifos nossos). Diante desta afirmativa, questionamos se, realmente, havia - no contexto da reforma curricular - um movimento contra o bacharelado. A professora continuou:

Não..Não! Acho que o movimento é muito mais agora, né? Agora quer ficar só a licenciatura, né? Mas aqui tem um objetivo de não se mexer no bacharelado porque realmente é um curso muito bom. Tem... Onde vão as pessoas que se submetem à pósgraduação, é aprovado... É um curso muito bom! (P.HIST2).

A percepção de que associa a reforma do curso de licenciatura a um movimento contrário ao curso de bacharelado foi constante na fala dos/as docentes entrevistados/as do Departamento de História. É interessante perceber que não existe evidência empírica nem mesmo menção a este tipo de movimento nas instruções normativas do Conselho Nacional de Educação - incluindo as instruções da própria UFPE -, tampouco nas falas das docentes do Centro de Educação. Isso nos leva a crer que, a despeito de não haver um dado concreto, a reforma curricular do curso de licenciatura soa como uma ameaça ao bacharelado.

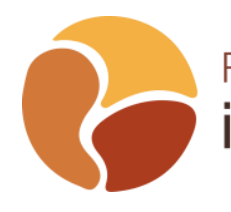


O trecho da entrevista com P.Hist3 deixou clara a noção de que a licenciatura com projeto próprio de formação, ou seja, com a formação pedagógica ampliada e dotada de componentes, contemplando novos e diversificados conhecimentos em relação ao que praticava modelo $3+1$, traz prejuízos à formação docente porque o conteúdo histórico é o mais importante no processo formativo e, por sua posição relativa no currículo reformulado estaria sendo secundarizado. Questionamos à docente se ela compreendia como necessária a reforma curricular do curso de licenciatura. De acordo com a mesma:

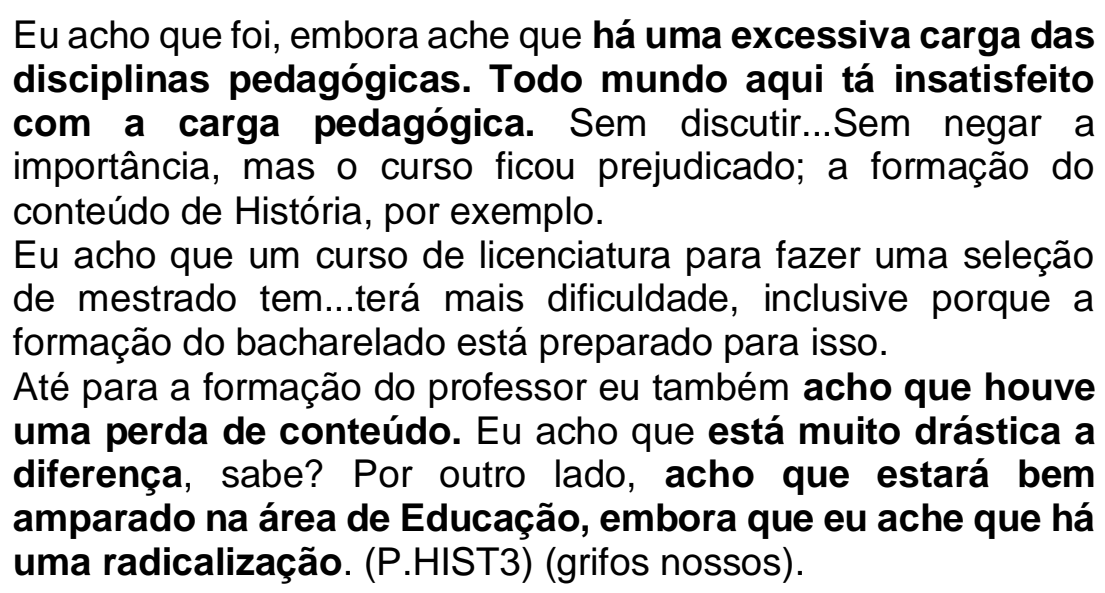

Diante da narrativa da docente, cabe-nos destacar dois aspectos considerados importantes em nossa análise. $O$ primeiro diz respeito à ampliação da formação pedagógica expressa no crescimento da oferta e da carga horária de componentes curriculares referentes ao campo da educação. Junto a isto, salientamos o aumento da diversificação de componentes curriculares da formação pedagógica que introduz conteúdos que não eram propostos para a formação dos/as licenciandos/as. O segundo ponto refere-se à revelação de que há comprometimento da formação do/a licenciando/a em relação a que é ofertada ao bacharel.

Para tratarmos da carga horária, faz-se necessário retomar informações sobre o perfil curricular anterior ao da reforma (o 1112-1), cuja organização tinha como base o modelo $3+1$. Nesse modelo, como já indicamos, a formação pedagógica configurava sua oferta no período final ao curso e como complementar ao bacharelado. Havia supremacia dos conteúdos históricos em relação aos do campo da educação - incluindo aqueles trabalhados no estágio supervisionado. Assim, a carga horária dos componentes curriculares da 
História totalizava $1365^{7}$ (mil trezentos e sessenta e cinco) horas, enquanto à formação pedagógica somava 600 horas.

Atualmente, no novo perfil curricular, existe uma distribuição relativamente equânime da carga horária dos componentes curriculares, ainda que os do campo da História permaneçam com um maior número de horas no conjunto do curso. A nova matriz curricular destina 1.110 (mil cento e dez horas) aos componentes curriculares da História e 1.080 (mil e oitenta) para os componentes curriculares da área de Educação; o que nos leva a crer que a crítica de docentes doD.H concentra-se na ampliação da carga horária da formação pedagógica e da autonomia do curso de licenciatura.

A tabela abaixo nos permite compreender o cenário da distribuição de carga horária referente aos componentes curriculares do campo da História e do campo da Educação dos perfis 1112-1 (anterior à reforma) e 1113-1 (posterior à reforma). Apresentamos também a carga horária destinada à produção dos Trabalhos de Conclusão do Curso (TCC), pois é capaz de sinalizara relevância da relação ensino-pesquisa proposta pelo currículo.

Tabela 01: Distribuição da carga horária dos componentes curriculares nos perfis 1112-1 e 1113-1 do curso de História da UFPE

\begin{tabular}{l|c|c}
\hline $\begin{array}{c}\text { CATEGORIA DE } \\
\text { COMPONENTE CURRICULAR }\end{array}$ & $\begin{array}{c}\text { CARGA HORÁRIA } \\
\text { (PERFIL 1112-1) }\end{array}$ & $\begin{array}{c}\text { CARGA HORÁRIA } \\
\text { PERFIL 1113-1 }\end{array}$ \\
\hline $\begin{array}{l}\text { Componentes históricos e } \\
\text { historiográficos }\end{array}$ & 1365 horas & 1110 horas \\
\hline $\begin{array}{l}\text { Componentes da formação } \\
\text { pedagógica }\end{array}$ & 600 horas & 1080 horas \\
\hline TCC & $x x$ & 120 horas \\
\hline
\end{tabular}

Fonte: produção de autoria da pesquisadora, com base em dados ofertados pelo site oficial da UFPE

Os dados apresentados na tabela mostram que ainda há predominância de carga horária referente aos conteúdos históricos e historiográficos, porém, o que gostaríamos de destacar é a ampliação da carga horária referente aos componentes curriculares da formação pedagógica que reflete a concepção de que ela é basilar à formação docente. Ressaltamos também a presença, no perfil 1113-1, de componentes curriculares voltados à produção do trabalho de conclusão de curso, pois os mesmos eram inexistentes no curso de licenciatura diante do perfil 1112-1.

\footnotetext{
${ }^{7}$ Neste somatório foram contabilizados apenas os componentes curriculares referentes ao campo da História. As áreas de conhecimento como Economia, Sociologia e Língua Portuguesa - situadas predominantemente no ciclo básico - não foram incluídas.
}

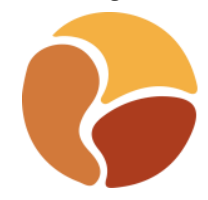


Estas questões elucidam nossa análise da concepção revelada por P.Hist3 sobre a reforma curricular do curso de licenciatura. Outro ponto mencionado pela docente P. Hist.3 refere-se à relação, até certo ponto paradoxal, entre a qualidade da formação dos licenciandos/as e o papel da formação pedagógica no currículo reformulado. $\mathrm{O}$ argumento utilizado é o de que 0 crescimento da carga horária dos componentes ofertados pelo Centro de Educação compromete a formação de professores/as como um todo. Identificamos, nesse ponto, uma problemática no atual processo formativo no curso de licenciatura em História da UFPE. Isto se deve ao fato do quadro docente, da área de História, ser o mesmo para ambos os cursos (bacharelado e licenciatura) e, mais ainda, os docentes apresentam a mesma prática e a mesma seleção de conteúdos para ambos.

Nos cursos de licenciatura, os conteúdos das áreas de referência não estão desassociados dos conteúdos da formação pedagógica. No caso do curso de História, a história escolar está imbricada aos debates historiográficos. A revisão dos conteúdos a serem ensinados nas escolas também acompanharia a revisão porque passa a historiografia. $O$ conhecimento de normas reguladoras da educação nacional, como a Lei de Diretrizes e Bases (LDB) e a Base Nacional Comum Curricular é fundamental para que se faça a devida aproximação entre as discussões forjadas no ambiente acadêmico e as propostas dos conteúdos escolares. No caso do curso de licenciatura em História da UFPE, os/as docentes do D.H possuem trajetórias de formação, pesquisa e ensino fincadas no bacharelado. Isto nos leva a duas possibilidades de intervenção para uma mudança efetiva no currículo - compreendendo o currículo como prática: ou há um investimento intensivo, por parte da instituição, na formação continuada dos docentes das áreas de referência, ou são feitas novas exigências no perfil formativo dos/as docentes/as que ingressam na Universidade em curso de licenciatura por meio de concurso público.

Acreditamos que, enquanto não houver o cumprimento de uma das duas propostas acima, será permanente o campo de disputa entre os projetos formativos propostos pelo Departamento de História e pelo Centro de Educação. Tendo por base os testemunhos colhidos por entrevistas e a análise documental - dados que se somam à nossa vivência de docente do curso de licenciatura mesmo com a separação formal entre o curso de licenciatura o do bacharelado, segue comprometida a prática curricular do primeiro curso, pois a formação no campo da História mantém a formação bacharelizante.

Quando perguntada sobre o desmembramento dos cursos, P.Hist2 afirmou:

Isso foi tranquilamente. Não houve esse problema. $\mathbf{O}$ aluno que fizesse bacharelado poderia complementar com a 
licenciatura, e o que fizesse licenciatura, podia fazer o bacharelado. Houve um desmembramento, mas não houve uma ruptura entre esses dois cursos. Então, não abalou muito, não. (P.HIST.2) (grifo nosso).

Chamamos atenção, no trecho da entrevista exposto acima, para a utilização do termo "complementar" quando a docente trata da licenciatura. O mesmo não acontece quando se refere ao curso de bacharelado. A professora sinaliza para o que afirmamos anteriormente, de que a manutenção de certas práticas pedagógicas curriculares não promove mudanças significativas na formação de professores/as no campo da História. A permanência de tais práticas está sustentada na concepção dos/as docentes de que esta é a melhor proposta para o processo formativo.

Também não acho que o professor só bacharel não tenha condições de estar numa sala de aula. Acho que tem! Ele tem várias formas de se apropriar dessa questão das ferramentas pedagógicas, mas acho que a formação tem que ser única. Tinha que ser a formação do historiador. Tinha que ser o curso de História. Volto até atrás: um curso de História onde você atuaria em duas frentes. Era o historiador que poderia atuar em outros campos, em outros locais como museus, arquivos e etc... (P.HIST4).

Aqui, mais uma vez, percebemos a defesa da priorização da formação para o bacharelado, pois, desta forma, o indivíduo estará apto a atuar em diversas instituições, inclusive nas escolas. Não pretendemos aqui estabelecer uma relação direta entre a formação do/a professor/a e a garantia de um bom desempenho em sua atividade profissional. Certamente, encontramos bacharéis que são considerados/as bons/as professores/as pelos seus estudantes, e licenciados/as que não são identificados/as como profissionais bem sucedidos/as em sua prática. Este não é o cerne da questão. O que pretendemos destacar é a compreensão trazida pelos/as membros - entrevistados - do Departamento de História de que o perfil bacharelizante é necessário para atuação profissional em diferentes campos de uma determinada área do conhecimento.

Eu vivenciei, em algumas reuniões, a crítica contundente do Departamento de História dizendo que nós "roubamos" carga horária do historiador e não havia como explicar para eles que não se trata de "roubar", mas de formar um profissional que é de um perfil diferente. Estamos formando um professor de História e não um bacharel em História. (P.CE1). 
A experiência relatada por P.CE1 nos mostra a resistência, por parte de docentes do Departamento de História, à separação dos cursos. Percebemos que a manutenção de certos componentes curriculares comuns aos dois perfis e de práticas pedagógicas curriculares repetidas em ambos os cursos alimenta a tentativa de dar ares de bacharelado ao curso de licenciatura, sugerindo um entendimento de que somente, deste modo, garante-se a relação ensinopesquisa.

Nesse sentido, P.CE2 chama atenção para a atuação do D.H na regulamentação do bacharelado: "eles querem uma melhor regulamentação para o bacharelado? Vá regulamentar o bacharelado. A licenciatura é um curso e o bacharelado é outro. Temos que assumir isso!" (P.CE2). Assumir que há uma formação específica para a licenciatura é um aspecto fundamental para que haja maior articulação entre os dois centros formadores de professores/as de História na UFPE. Diante de tal articulação, a relação ensino-pesquisa também é redimensionada, pois se compreende que o curso de licenciatura também promove a prática da pesquisa e que a área de Educação também é campo de investigação e não de aplicação de teorias.

Eu acho que as pessoas, no geral dos departamentos âncora, por não terem contato com o Centro de Educação, elas não conhecem o conceito de professor pesquisador. E o conceito de professor é de 'dador' de aula, adestrado para o domínio do objeto. (P.CE2).

O debate sobre a articulação entre o Departamento de História e o Centro de Educação nos conduz a pensar sobre a temática da relação entre os saberes disciplinares e saberes pedagógicos na formação docente. Autores como Batista Neto (2007); Monteiro e Penna (2011) nos chamam atenção para o desafio da formação e da prática de ensino História no que concerne ao diálogo entre os múltiplos saberes da docência, especialmente os disciplinares e pedagógicos. Segundo Monteiro e Penna (2011), o ensino de História está situado num "lugar de fronteiras" no qual a produção de saberes deriva dos "diálogos, trocas e reconhecimentos das diferenças." (p.191).

Partindo de tal compreensão teórica e dos testemunhos de membros dos departamentos responsáveis pela formação do/a professor/a de História da UFPE, identificamos que a relação ensino-pesquisa traz à tona, de permeio, o debate acerca da relação entre os saberes docentes no processo formativo. Os depoimentos acerca da valorização do perfil de caráter bacharelizante, por parte de docentes do Departamento de História, nos levaram a questionar de que maneira o diálogo entre os saberes docentes vem sendo compreendido - e 
expresso enquanto prática pedagógica - diante da reforma curricular que sugere uma formação própria para licenciandos/as.

O docente P. Hist1 afirmou que compreende a importância da interlocução dos saberes disciplinares com os da formação pedagógica. Admite que seria importante a ressignificação de sua prática para as turmas de licenciatura, tendo em vista que o saber acadêmico será também reconceptualizado pelos/as professores/as em formação para se tornar saber escolar. Mesmo em face desta leitura, P.Hist1 constata que as práticas de ensino dos professores formadores ainda estão arraigadas, majoritária e preferencialmente, ao trabalho com saberes disciplinares, com pouco diálogo com o campo educacional. Isso não o impede de construir a crítica a essa prática.

\begin{abstract}
Acho que [em] todos os cursos, nós temos nossos problemas e nossas virtudes. Nosso professorado é um professorado...Não é um que se esmere na formação pedagógica. Eu acho que nenhum de nós. Eu mesmo...No sentido de ter aquele investimento em encontrar uma estratégia de abordagem do assunto que atendesse à perspectiva do aluno. Todos nós, pelo menos, a imensa maioria de nós, somos o que chamariam de conteudistas.

O que importa é ter o domínio de um conteúdo e se eu domino um conteúdo, eu sou, necessariamente, um bom professor. Então, não preciso me preocupar para além disso. Eu acho que é um problema grande nosso. Nem só de História, nem só da UFPE. (P.HIST1).
\end{abstract}

O trecho da entrevista do professor nos convida a refletir sobre a prática pedagógica de docentes formadores. Levanta também o debate acerca do que seria um/a "bom/a professor/a" formador/a. Estas temáticas têm profunda relevância para o debate educacional e, certamente, merecem atenção em futuras análises que se desdobrarão desta pesquisa, porém, nos propomos aqui a pensar acerca da relação entre os saberes construídos no campo na História e os saberes do campo educacional no processo formativo dos/as licenciandos/as. Segundo o docente, a interlocução é defasada porque sua própria prática, e a prática de seus pares, carecem do diálogo.

A ausência da relação dialógica pode ser justificada pelo distanciamento dos/as docentes dos departamentos âncoras ao debate educacional. No caso do curso de História, indicamos anteriormente que a carreira acadêmica dos docentes, em sua grande maioria, tem suas bases fincadas no bacharelado. Se utilizarmos os sujeitos de nossa pesquisa como significativos do que pensa 0 Departamento de História, percebemos que dos quatro docentes entrevistados, apenas uma apresentou interesse para com o debate educacional, e este interesse se originaria de questões de

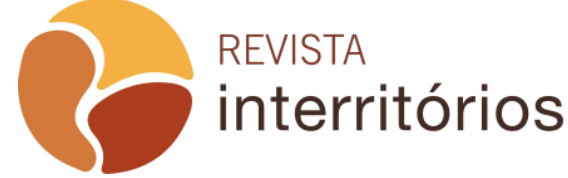

Interritórios | Revista de educação Universidade Federal de Pernambuco, Caruaru, BRASIL | V. 6 n. 11 [2020] 
empatia, gosto pessoal e trajetória profissional. Os demais mantiveram certa distância com o campo de conhecimento com o qual compartilham com outros a formação dos/as licenciandos/as, o que, seguramente, tem dificultado com que conheçam os saberes desse mesmo campo.

Segundo P.CE1, o diálogo com o campo da Educação faz-se necessário até mesmo no curso do bacharelado, tendo em vista que as discussões historiográficas são base para a construção do saber histórico escolar e, dentro disso, pautam a produção de materiais didáticos e artefatos culturais que são utilizados como recursos.

E vamos combinar: para que serve uma pesquisa que não é direcionada a aprendizagem de alguém? Então, até mesmo o bacharel deveria ser formado com uma sensibilidade educativa (...) Os historiadores franceses são todos professores de Escola Normal. Inclusive, os historiadores brasileiros que se dizem influenciados por eles têm pavor à escola. Eles estão de costa para a educação, em especial para a educação pública. (P.CE1).

A relação deficitária entre os saberes do campo da História e os saberes pedagógicos também aparece em pesquisas que tem o ensino de História como objeto de investigação. De acordo com Monteiro e Penna:

De modo geral, as pesquisas que têm como objeto o ensino de história e utilizam os referenciais oriundos da história ou da educação, deixam de fora reflexões teóricas importantes, seja sobre a especificidade da prática pedagógica, seja sobre a especificidade da disciplina ensinada - a história. Por isso, defendemos que a pesquisa sobre o ensino de história constitui-se em lugar de fronteira no qual se busca articular, prioritariamente, as contribuições desses dois campos, essenciais para se problematizar o objeto em questão. (MONTEIRO \& PENNA, 2011, p. 192) (grifo nosso).

Embora o ensino de História não se configure como nossa categoria central de análise, a temática vem à tona quando discutimos a relação entre saberes disciplinares e saberes pedagógicos. As questões trazidas pelos/as docentes entrevistados/as nos levam a questionar em que medida essa articulação é concebida pelos docentes formadores e de que maneira ela pode contribuir para um (re)direcionamento dos conteúdos a serem ensinados e de práticas dos/as professores/as formados/as no curso de licenciatura. Quando foi arguida sobre os desafios de ser professora no curso de licenciatura, P.Hist3, disse: 
O desafio de integrar os conteúdos que se renovam cada vez mais das disciplinas que a gente ensina para o exercício do ensino mesmo; para a prática pedagógica. Porque eu percebo que a gente vê muita coisa diferente, que não se dá mais, não é? Que se questiona, mas eu acho que as discussões complexas, que envolvem alguns temas, não vai (sic) chegar lá na sala de aula. Ninguém vai explicar a discussão sobre é... Se o pacto colonial existiu ou não, mas, na prática, vai dizer o de sempre: o pacto colonial!

Eu acho muito difícil o que eu ensino...eu ensino na sala de aula para os meus alunos e do que eles vão poder pensar mais adiante...porque eles vão passar a proposta mais bitolada do conhecimento histórico; quando a gente já problematiza cada tema cada vez mais, mas como fica isso no Ensino Médio? Quando chega a hora, vem a Revolução Francesa como revolução burguesa e foi assim, assim... O pacto colonial...Continua tudo a mesma coisa. (P.HIST3).

O trecho da entrevista nos aproxima de uma discussão cujo eixo é a relação entre a universidade e a escola - parte fundamental do debate acerca da relação ensino-pesquisa - onde a academia é concebida como espaço produtor de conhecimento e a escola como mero reprodutor. A professora expressa, com clareza, que a escola difunde conhecimentos defasados, que passa ao largo dos mais recentes debates historiográficos e que os faz não só por desconhecimento, mas por esforço do/a professor/a da educação básica de simplificar o que the parece complexo. Seguindo essa linha de compreensão, a história escolar seria uma adaptação, cercada de equívocos e atrasos historiográficos, daquilo que se produz na Universidade. De acordo com Chervel,

muda, evidentemente, a partir do momento em que izações ou adaptações. Pois as disciplinas de ensino historiativeis por natureza a essas categorias funcionamento colrom he imediato constituição e seu problemas. O primeiro é o de sua gênese. Como a escola, sendo a partir daí desqualificada toda outra instância, começa a agir para produzi-las? O segundo refere-se à sua função. Se a escola se limitasse a "vulgarizar" as ciências ou a adaptar à juventude as práticas dos adultos, a transparência dos conteúdos e a evidência dos seus objetivos seriam totais. Já que ela ensina suas próprias produções, não se pode senão se questionar sobre suas finalidades: elas servem para quê? Por que a escola foi levada a tomar tais iniciativas? Em que determinada disciplina responde à expectativa dos pais, dos poderes públicos, dos que decidem? 
Terceiro e último problema, o do seu funcionamento. Aqui, ainda, a questão não teria sentido se a escola propagasse a vulgarização para reproduzir a ciência, o saber, as práticas dos adultos: a máquina funcionaria tal e qual, e imprimiria nos jovens espíritos uma imagem idêntica, ou uma imagem aproximada, do objetivo cultural visado. Ora, nada disso se passa no quadro das disciplinas. Não, certamente que não haja aí um objetivo. Simplesmente, constata-se que, entre a disciplina escolar posta em ação no trabalho pedagógico e os resultados reais obtidos, há muito mais do que uma diferença de grau ou de precisão (CHERVEL, 1990, p. 184) (grifos nossos).

Como se sabe, o trabalho de pesquisa do autor se insere no domínio da história das disciplinas escolares. Neste contexto, Chervel chama-nos atenção para a ideia que se guarda da disciplina escolar como uma adaptação ou vulgarização da ciência. No caso da história escolar, seria uma adaptação simplificada do que se produz no campo historiográfico. A tese do autor põe em xeque as concepções que enxergam o ensino de História como um campo mecânico de reprodução ao invés de ser ele mesmo produtor de conhecimentos didático pedagógicos, portanto de existência concomitante a prática de investigação da História com o da prática escolar de ensino da História. A história escolar é, portanto, uma outra categoria de conhecimento cuja construção está permeada por diversos saberes - inclusive, os saberes pedagógicos - e suas referidas práticas de mobilização.

O saber pedagógico, portanto, não se relaciona com o saber disciplinar ou com os demais saberes de forma a complementar os mesmos. Ele é parte integrante fundamental da construção de conteúdos escolares, materiais didáticos e práticas pedagógicas, constituindo, ela também, o campo da pesquisa educacional. Ou seja, a formação docente precisa estar forjada numa relação dialógica entre saberes diversos, de modo a não compreendermos a escola como mero ambiente reprodutor e a formação pedagógica como mera facilitadora de compreensões dos conteúdos acadêmicos.

A formação de História é uma formação de gerações, de cidadania. História forma cidadãos. Você se acha no Egito; você se acha na Itália; você se acha na...no Renascimento, no Chile, na China, na América Latina, você se acha! Então, você se identifica para saber o teu papel. Então, História tem um papel de educar o cidadão, de construir o cidadão. Ela forma muito a cidadania, né? O cidadão...conscientizando de ser crítico.

Acho, inclusive, que a pedagogia veio para facilitar porque possibilita sistematizar um conhecimento que é repassado para passar para o nível que você vai dar, seja no Ensino Fundamental, seja no Ensino Médio. Não é que eu ache incompatibilidade, não. Eu acho que não dá para você trabalhar 
o pedagógico sem saber o conhecimento específico. (P.HIST2) (grifos nossos).

A concepção trazida pela docente reforça o que dissemos, em outro momento, que os/as docentes entrevistados/as do Departamento de História não negam a importância da formação pedagógica na licenciatura. A questão está em como os/as docentes enxergam esta formação e sua relação com os saberes disciplinares. Em um dado momento da entrevista, a professora P.Hist4 sinalizou a importância dessa formação para o curso de licenciatura, que tem a escola como elemento norteador.

Como sou eu que to dando TCC1, então a gente é que seleciona o que trabalha, né? Para mim, um aluno de licenciatura, ele tem que articular esse conhecimento histórico ao conhecimento pedagógico porque o foco dele é a escola, então ele vai ter que intervir nesse espaço. Toda discussão do Projeto Pedagógico foi em função disso porque a grande questão era a licenciatura. Não estava em xeque se ficava o bacharelado ou não. O projeto que eu participei, o foco era a licenciatura porque aumentou um número muito grande de aulas, de carga horária.

Quando eu trabalho paleografia agora, como meu xodó, minha cachaça é a educação, eu dou paleografia como recurso, como estratégia metodológica para ele trabalhar com documentos. Então, o trabalho dos meninos ao invés de fazer um artigo é fazer um plano de curso incluindo paleografia, incluindo os documentos.

Eu faço da aula, oficina. Os alunos de História estudam paleografia, mas a aula tem um olhar voltado para a sala de aula. (P.HIST4).

Mesmo admitindo que o foco da formação docente seja a escola, na sequência de sua entrevista, a docente não deixa de criticar a ampliação da formação pedagógica a partir da reforma curricular.

A carga horária pedagógica ficou muito alta para a licenciatura e a gente não queria que o aluno perdesse essa...deixasse de se apropriar do conhecimento histórico propriamente dito. Então, ele não poderia se afastar apenas com as teorias pedagógicas, ele tinha que trabalhar essa teoria articulada ao conhecimento da História, à nova historiografia, às discussões historiográficas, como é que se dá o debate historiográfico sobre determinados termos e isso com um olhar voltado para a sala de aula. (P.HIST4). 
Os estudos como os de Bittencourt (2004) e Fonseca (2005) abordam a relação entre a produção historiográfica e o ensino de História. Os debates em torno da historiografia recaem sobre o ensino de História na medida em que se reveem conceitos e análises. Com base nos estudos de Tardif (2002), reforçamos a compreensão de que não há docência desprovida de saberes disciplinares ou de saberes qualquer outro tipo. O que buscamos destacar aqui é a ideia levantada por docentes do Departamento de História de que, para a formação de professores/as, o saber disciplinar é soberano, enquanto os saberes da formação pedagógica são coadjuvantes.

No caso de P.CE1, sua concepção vai de encontro ao que é defendido pelos/as docentes do D.H, sujeitos da pesquisa. Segundo a docente, a formação pedagógica deve ser o foco do processo formativo porque é ela quem trata, especificamente, do trabalho exercido pelos professores em sua prática pedagógica. "As disciplinas relacionadas às aprendizagens; de ensino, de avaliação devem ser priorizadas porque é a lida do professor" (P.CE1).

A docente prossegue analisando a relação entre os saberes disciplinares e os saberes da formação pedagógica:

Você não aprende conteúdo para depois ensiná-lo. Os conteúdos com os quais você trabalha na graduação, todos eles têm que ser passados e submetidos à luz do que você vai ensinar. Então, você tem que tá articulado com a escola; com sistema de ensino. Você tem que tá articulado com o aluno de alguma maneira. Você imagina um médico passar seis anos na Universidade e só no último ano ir atender as pessoas. É essa a proposta desse tipo de perspectiva que acredita que você acumula para depois você transmitir, como se pressupõe que a docência é transmissão e não construção de conhecimento. (P.CE1).

Se analisarmos, conjuntamente, as entrevistas das docentes P.Hist4 e P.CE1, iremos nos aproximar de questão levantada por Tardif (2002) quando diz que 0 debate sobre os saberes docentes pode cair em dois extremos: 0 pedagogismo e o conteudismo. $O$ pedagogismo refere-se à supremacia da formação pedagógica e o esvaziamento do saber disciplinar. O conteudismo, por sua vez, faz o caminho inverso, pois tende a silenciar os saberes pedagógicos e valorizar os saberes disciplinares. Acreditamos, assim como Batista Neto (2007), que um ponto de maior complexidade do processo formativo está em construir pontes de diálogo e articulação entre esses dois tipos de saberes.

Ao mesmo tempo que afirmamos a necessidade de articulação de saberes no currículo do curso de licenciatura, corroboramos com a fala de P.CE1 quando esta afirma que o processo formativo fica comprometido quando

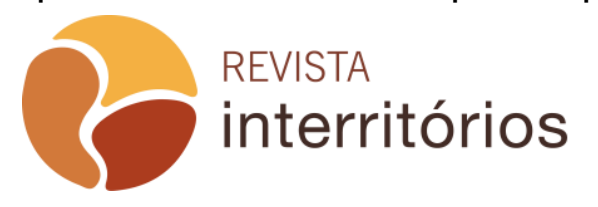

Interritórios | Revista de educação Universidade Federal de Pernambuco, Caruaru, BRASIL | V. 6 n. 11 [2020] 
partimos do princípio da aplicabilidade do conhecimento. A prática aplicacionista na formação de professores/as concebe o saber disciplinar como campo teórico que deve ser acumulado e aplicado, posteriormente, nas escolas pelos/as professores/as através de seus saberes da formação pedagógica que são entendidos, assim, como puramente utilitaristas.

\section{Considerações Finais}

A relação ensino-pesquisa ganhou destaque na análise de docentes e do funcionário do corpo técnico administrativo quando questionados/as acerca da formação pedagógica do/no curso de licenciatura em História da UFPE. Percebemos que houve divergências entre os sujeitos da pesquisa que testemunharam sobre o currículo do curso e o processo de reforma. Os distanciamentos eram nítidos no que concerne às compreensões daqueles/as vinculados ao Departamento de História e ao do Centro de Educação. No caso dos/as docentes do $\mathrm{DH} / \mathrm{CFCH}$, a pesquisa foi vista como uma atividade própria do campo da História e a ele deve cingir-se quando se trata de desenvolver atividades de investigação com estudantes em formação de professor/a. $O$ ensino foi compreendido como uma categoria da responsabilidade exclusiva do Centro de Educação. Segundo os/as professores/as de História, o objetivo do curso seria formar um/a "professor/a historiador/a", entendido/a com aquele/a em que se construiu uma sólida formação em termos de saberes disciplinares do campo da História.

A noção de "professor/a historiador/a" esteve ancorada, primeiramente, na ideia de que o prestígio do curso de História decorre do bacharelado. Além disso, tal concepção corrobora com o que dissemos anteriormente sobre a perspectiva de que a pesquisa só venha a acontecer se incidir sobre objetos históricos. Entre os sujeitos vinculados ao Departamento de História não houve menção quanto à possibilidade de se realizar pesquisa sobre problemas educacionais, invisiblizando-se assim o papel dos saberes pedagógicos na formação do/a professor/a de História.

As docentes do CE, por sua parte, apontaram a indissociabilidade entre ensino e pesquisa como condição fundamental para a formação de professores/as. Todavia, reiteraram que a marca distintiva do curso de licenciatura é a pesquisa educacional. Isso quer dizer que se o curso está situado no campo da Educação, este deve ser o campo de pesquisa dos/das docentes em processo formativo. Percebemos, portanto, que a formação de professores/as de História da UFPE vem sendo construída com base em um campo de disputa cujo foco é o processo formativo. 


\section{REFERÊNCIAS}

BARDIN, Laurence. Análise de Conteúdo. São Paulo: Martins Fontes, 1977.

BATISTA NETO, José. Saberes Pedagógicos e Saberes Disciplinares Específicos: os desafios para o ensino de História. Fóruns Contemporâneos de Ensino de História no Brasil | on-line. 2007.

BITTENCOURT, Circe Maria Fernandes. Ensino de História: fundamentos e métodos. São Paulo: Cortez, 2004.

CHERVEL, André. História das disciplinas escolares: reflexões sobre um canto de pesquisa. Teoria e Educação. Rio Grande do Sul, n.2, 1990, p. 177-229.

CUNHA, Maria Isabel da. Indissociabilidade entre ensino e pesquisa: a qualidade da graduação em tempos de democratização. PERSPECTIVA, Florianópolis, v. 29, n. 2, 443-462, jul./dez. 2011.

FONSECA, Selva Guimarães. Didática e Prática de Ensino de História. São Paulo: Papirus, 2005.

FREIRE, Paulo. Professora, sim; tia, não - Cartas a quem ousa ensinar. São Paulo: Olho D’água, 1997.

MINAYO, Maria Cecília de Souza. O Desafio do Conhecimento - Pesquisa Qualitativa em Saúde. São Paulo: Editora Hucitec, 2006.

MONTEIRO, Ana Maria Ferreira da Costa; PENNA, Fernando de Araújo. Ensino de História: saberes em lugar de fronteiras. Educ. Real., Porto Alegre, v. 36, n.1, p. 191-211, jan./abr., 2011.

SOARES, Sandra Regina; CUNHA, Maria Isabel da. Qualidade do ensino de graduação: concepções de docentes pesquisadores. Avaliação, Campinas; Sorocaba, SP, v.22, n.2, p.316-331, jul, 2017.

TARDIF, Maurice. Saberes docentes e formação profissional. Petrópolis, RJ: Vozes, 2002. 